\title{
Thermal design and full-scale thermal response test on Energy Walls
}

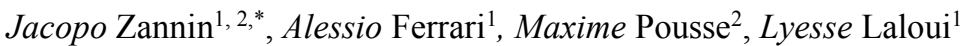 \\ ${ }^{1}$ Swiss Federal Institute of Technology in Lausanne, Lausanne, Switzerland \\ ${ }^{2}$ Nobatek, Esplanade des Arts et Métiers / Site ENSAM, Talence, France
}

\begin{abstract}
Energy geostructures (EG) are an innovative technology in the sustainable energy agenda that can be used to satisfy the heating and cooling needs of the built environment. EGs include several types of geostructures such as piles, walls, tunnels, shafts, sewers. The application of this technology to infrastructure projects is particularly interesting because of the important thermal potential offered by the large surfaces that can be thermally-activated. This study deals with thermo-active walls (Energy walls, EW), which are retaining structures used to sustain the sides of excavations. Aspects related to the hydro-thermal interactions and to the thermal design are here presented. Finally, the testing setup for the execution of a thermal response test on a recently-built EW in western Switzerland is discussed.
\end{abstract}

\section{Introduction}

Geothermal energy is recognized to be one of the most important renewable and sustainable energy sources on earth [1]. This work relates on a particular type of shallow geothermal applications: energy geostructures (EG). EG employ regular geostructures with heat exchanger loops secured to the reinforcing cage. The heat exchangers are connected to a heat pump and then to a secondary circuit forming a ground source heat pump system (GSHP). Some of the main advantages of such technology are that (i) energy is continuously available, regardless of weather conditions, (ii) shallow geothermal is available almost everywhere and (iii) a wide range of applications exist. Among various types of EG, this study focuses on energy walls (EWs). EWs are reinforced concrete embedded geostructures used to sustain the sides of excavations and represent a relatively new technology in the field of EGs.

Despite of the available literature, a number of challenges still exist. Particularly, understanding the heat exchange mechanisms is of primary importance and, secondly, there is a clear lack of monitored full-scale installations whose feedback would be useful to clarify the thermo-hydro-mechanical behaviour of EWs.

This study deals with the hydro-thermal interactions between the wall and the surroundings and proposes a methodology for thermal design. Finally, the execution of a thermal response test (TRT) is described.

\section{Thermal design of energy walls}

The study of the thermal behavior of EGs is built on a sound understanding of what is acting around the geostructure. Within EWs, hydro-thermal interactions are not properly understood in the available literature. This study aims at closing this gap by tackling the problem from different scales: from the infrastructure scale to the heat exchanger scale highlighting possible mutual interactions and detecting the consequent variations in terms of the thermal behavior. As a consequence, some additional considerations can be done and an early-stage thermal design methodology can be proposed. Fundamental aspects related to hydro-thermal interactions are analysed accounting for the different time-dependent processes of different typical durations taking place within EG operations. The hydro-thermal behavior of soil is described through an analysis of the 3D non-isothermal seepage problem. These evaluations are essential in order to estimate the thermal potential of a site with an EW installation. A design methodology with a sound theoretical basis that links heat transfer, fluid dynamics and seepage in porous media is presented by means of a flowchart, that gives to a designer a quick tool to perform preliminary energy calculations in order to detect the impact of applying the EW technology on a planned infrastructure. The early-stage thermal design of an EG is strongly linked to the decision making process: a budget analysis and an estimation of the energy quantities achievable with EG will give a first, preliminary, acceptance (or not) of employment of such technology. If the use of EG is rejected at this stage, the probability to re-schedule the thermal activation at an advanced stage of the project dramatically decreases. On the contrary, if a designer can quickly and reliably demonstrate the advantages offered by EGs, the possibilities to include thermo-active geostructures on an infrastructure project, considerably increase.

\footnotetext{
Corresponding author: jacopo.zannin@epfl.ch
} 

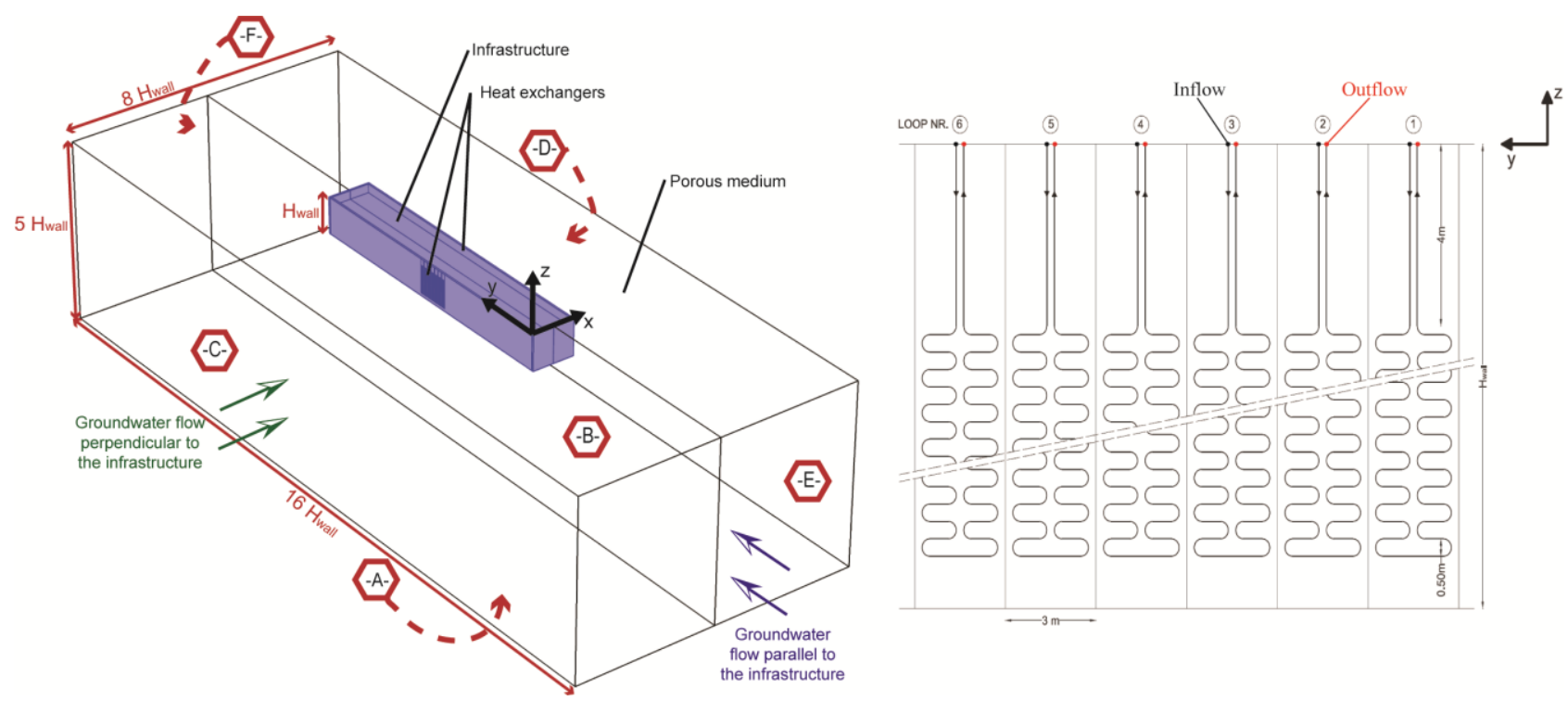

Fig. 1. 3D finite element model (left) and detail of the heat exchangers (right). The boundaries are numbered as follows: -A- bottom; -B- top; -C- left; -D- right; -E- front; -F- back

\subsection{D finite element modelling}

The tool used for tackling the problem is finite element modelling. A 3D hydro-thermal model of an infrastructure is built using the commercial software Comsol Multiphysics@ [2]. Fig. 1 (left) shows the model features. Hydraulic and thermal boundary conditions are set in order to impose selected groundwater flow directions (parallel and perpendicular to the wall) and magnitudes. The mathematical formulation in the soil mass and concrete is governed by the mass balance equation of the fluid phase, the Darcy Law and the energy conservation equation. A number of heat exchanger pipe loops (Fig. 1, right) are modelled as linear entities and the nonisothermal fluid flow is included following the formulation proposed in [3-6]. The non-isothermal fluid flow in the pipes is governed by the energy conservation equation and Navier-Stokes equations for the incompressible fluid flow in pipes.A number of thermal and hydraulic boundary conditions are applied. Referring to the boundaries numbered in Figure 1 (left), two variants of the model have been setup in order to simulate the groundwater flow parallel and perpendicular to the infrastructure.

For the case of groundwater flow perpendicular to the infrastructure, the following thermal boundaries have been defined: - $\mathrm{A}$ - and $-\mathrm{C}$ - have a constant temperature of $15^{\circ} \mathrm{C}$; -B- a temperature that varies between $0^{\circ} \mathrm{C}$ and $30^{\circ} \mathrm{C}$ for different runs aiming at encompasses surface temperatures of different climates; -D-, -E- and -F- are adiabatic. The hydraulic boundary conditions are set as follows: -A-, -B-, -E- and -F- are set as impervious; -Chas a constant total hydraulic head, $\mathrm{H}$, of $\mathrm{H}=-4 \mathrm{~m}$; -Dpresent a $\mathrm{H}$ that varies between $-5 \mathrm{~m}$ and $-9 \mathrm{~m}$ for different runs in order to encompass different values for the average groundwater flow velocity.

For parallel groundwater flow, the following thermal boundaries are set: -A- and -E- have a constant temperature of $15^{\circ} \mathrm{C}$; -B- a temperature that ranges between $0^{\circ} \mathrm{C}$ and $30^{\circ} \mathrm{C}$ for different runs; -C-, -D-, -F- are adiabatic. The hydraulic boundaries are set as: -A-, -B-, $\mathrm{C}$-, -D- are impervious; -E- has a $\mathrm{H}=-4 \mathrm{~m}$ and in the border $-\mathrm{F}-\mathrm{H}$ varies between $-7 \mathrm{~m}$ and $-18 \mathrm{~m}$.

The solution is divided into two solvers: initially, the hydraulic and thermal boundary conditions are activated and solved by means of a stationary solution. Secondly, a time-dependent solution which takes the solution of the stationary solver as initial condition and then accounts for the thermal activation of the EW takes place. The thermal activation consists in enabling the non-isothermal fluid flow in pipes to occur. The thermal input consists in the application of a constant with time fluid velocity and temperature at the pipe inflow (Fig. 1, right) for winter and summer operation modes (Fig. 2). In order to get comparable results between winter and summer operations and knowing that the average undisturbed soil temperature is of $15^{\circ} \mathrm{C}$ (as from the applied thermal boundary conditions), the imposed temperatures at the pipe inflow are set to $5^{\circ} \mathrm{C}$ and $25^{\circ} \mathrm{C}$ for winter and summer operation, respectively. This is done in order to achieve an initial temperature variation of $\pm 10^{\circ} \mathrm{C}$ between the soil and the heat carrier fluid. The heat carrier fluid velocity is set to $0.5 \mathrm{~m} / \mathrm{s}$ [6].

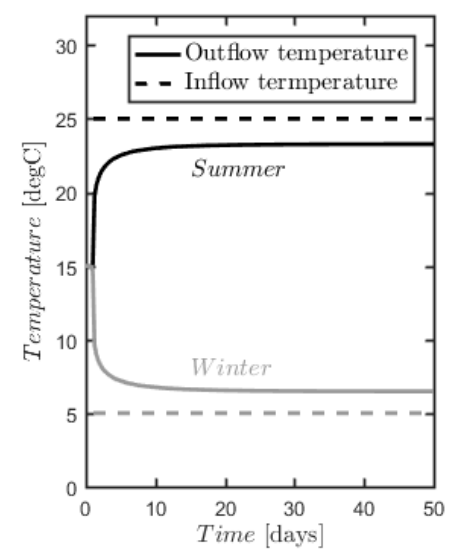

Fig. 2. Thermal input applied at the pipe inflows (Fig. 1, right)

\footnotetext{
* Corresponding author: jacopo.zannin@epfl.ch
} 


\subsection{Fundamentals on hydro-thermal interactions}

In the case of groundwater flow perpendicular to the wall, the groundwater intercepts the wall and a seepage around the geostructure takes place (i.e. water flows downwards, then below the tunnel and finally upwards again on the other side of the tunnel). The heat is moved consequently following the seepage flow. No remarkable variations of the seepage flow are recorded due to the small magnitude of the groundwater flow induced by the seepage in the vicinity of the wall (Figure 3). More interesting is the case of groundwater flow parallel to the wall, because the distribution of water density and dynamic viscosity induce a circular groundwater motion aside of the thermoactive wall at the wall-soil interface (in the $x z$ plane). Moreover, the main direction of groundwater velocity is directed on $y$ direction. A local variation of the flownet takes place: a variation of the vertical component of the velocity vector $\left(\mathrm{v}_{\mathrm{f}, \mathrm{z}}\right)$ is recorded. During wall heating, the velocity vector shows a component upwards directed, the opposite during wall cooling.

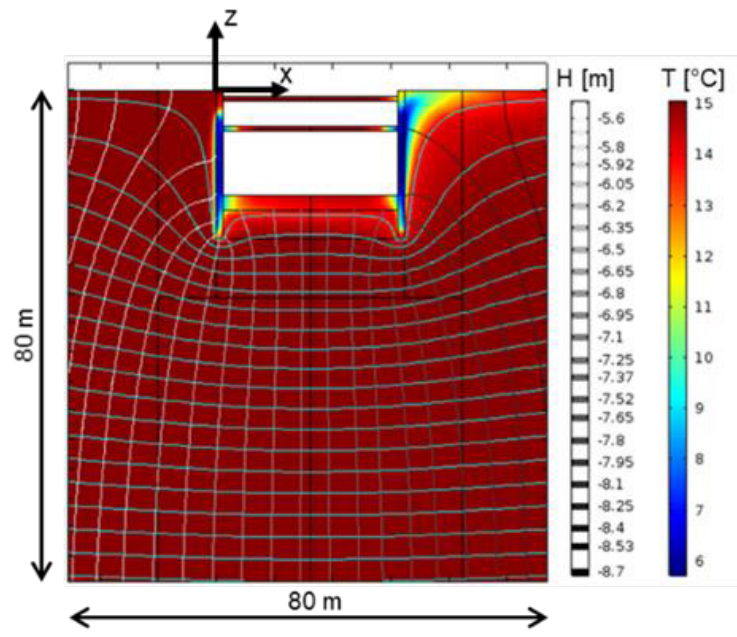

Fig. 3. Zoom-in in the vicinity of the infrastructure: temperature contour plot during winter geothermal operation with indication of the equipotential lines of the hydraulic head $(\mathrm{H}$, grayscale) and the streamlines (cyan) for the case of groundwater flow perpendicular to wall

The magnitude of $v_{f, z}$ depends only on the temperature difference between the thermo-active wall and the undisturbed soil temperature. The variation of this component may reach $\Delta \mathrm{v}_{\mathrm{f}, \mathrm{z}}=0.4 \mathrm{~m} / \mathrm{d}$. Moreover, the seepage effect is interacting with the power extraction/injection rate of the heat exchangers: the seepage moves the heat in the flow direction, the soil temperature varies along the y direction, interacting with the power extraction/injection of subsequent pipe loops. On one side, a higher groundwater flow velocity guarantees a higher heat exchange, but at the same time hydraulically-induced thermal interactions among consequent pipe loops take place, affecting the thermal behaviour of consequent heat exchanger loops [7].

\subsection{A flowchart for early-stage thermal design}

An extensive campaign of analyses has been carried out in order to account for thermal and hydraulic environments typical of EG-related cases, and the results in terms of thermal behaviour of the heat exchangers have been used to propose a methodology for the early-stage thermal design based on a flowchart [8].

The flowchart requires the knowledge of basic, average hydro-thermal properties of a site and gives, as output, an estimation of the power extraction/injection rate expressed per square meter of thermo-active geostructure (Fig. 4).

A user enters the flowchart with the magnitude of the groundwater flow velocity of the site and this gives an estimation of the main heat transfer regime (conduction or convection). Then, by defining the average thermal conductivity of the soil mass, an estimation of the power extraction/injection rate (in $\mathrm{W} / \mathrm{m}^{2}$ ) is given.

\section{Full-scale thermal response testing}

TRT is a type of testing that is being used since few decades [9-11]. It has been used mainly for vertical heat exchangers such as boreholes and energy piles. The goal of TRT is to determine the average thermal parameters of a soil mass. A pile (or borehole) is constructed, with the pipe loop embedded in a grout. The two ends of the pipe loop are connected to a heater. The first part of the test relates to the determination of the average undisturbed temperature of the soil mass simply by circulating the heat carrier fluid in the pipes. The second phase relates to the application of a constant thermal power which is monitored by the heating unit. Typical test duration is around 15 days, in order to attain a steady state (for boreholes and piles). Average thermal properties of the soil mass are then estimated by the analysis of the test results by using analytical and semi-analytical formulations. Various standards are nowadays available worldwide on this topic, such as the Thermal Pile standards, by the GSHP Association (UK) [12].

For the case of EWs, little is known on this topic. Few examples are available in the literature [13]. The construction phases of walls complicate the test execution, interpretation and sometimes it is not feasible to perform the test after the excavation phase. Moreover, the data interpretation is not easy due to the complicated geometry.

As a consequence, the definition of the TRT execution on EW is a hot topic for research. The objectives could be revisited: on one hand the determination of thermal parameters of the soil mass are one option, on the other the objective could be the estimation of preliminary energy quantities useful for a future energy exploitation. Depending on the objective, the execution details may differ. 


\section{CONVECTIVE-DOMINATED REGIME}

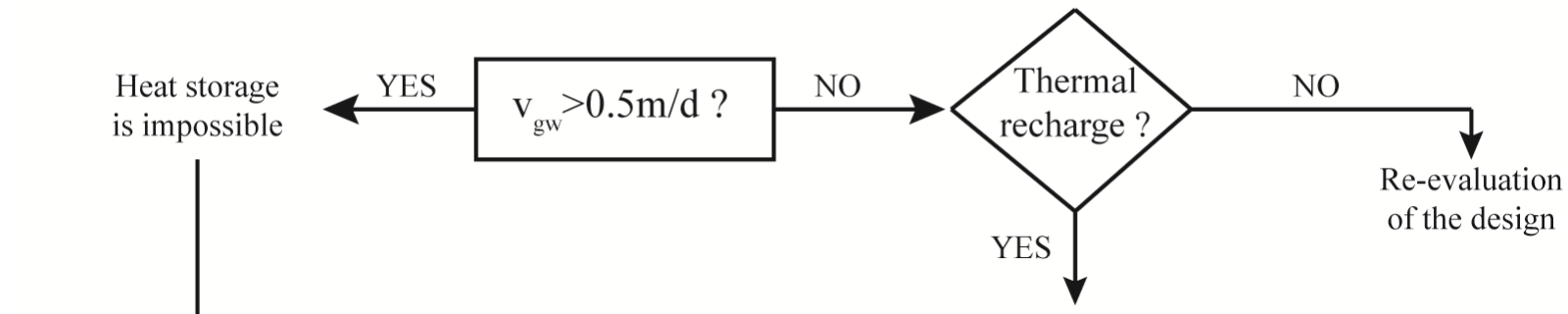

Cooling and heating needs should be similar in order to avoid soil freezing or increasing temperature in the long term

\begin{tabular}{|c|c|}
\hline$\lambda \mathrm{s}[\mathrm{W} / \mathrm{m} / \mathrm{K}]$ & $\dot{q}\left[\mathrm{~W} / \mathrm{m}^{2}\right]$ \\
\hline$<2.5$ & $15-20$ \\
\hline$>2.5$ & $>25$ \\
\hline
\end{tabular}

\begin{tabular}{cc}
\hline$\lambda \mathrm{s}[\mathrm{W} / \mathrm{m} / \mathrm{K}]$ & $\dot{q}\left[\mathrm{~W} / \mathrm{m}^{2}\right]$ \\
\hline$<2.5$ & $5-15$ \\
& \\
$>2.5$ & $15-25$ \\
\hline
\end{tabular}

Fig. 4. Flowchart for early-stage thermal design

\subsection{Heat exchange modes}

In addition to the geometrical and construction constraints that affect the case of EWs, the thermal exchanges involved in EW operation are quite complex because of the involved materials. Conduction and convection take place within the fluid flow inside the geothermal pipes and the pipes wall. Conduction is again predominant inside the concrete. Below the excavation line, the wall is surrounded by soil on both sides, hence conduction is generally the main heat exchange mode. Convection may be predominant if an important groundwater flow is present. Above the excavation line, the wall is facing the soil on one side and the air on the other. In the soil, the same heat exchange modes previously described apply, while at the concrete air interface convection takes place because of the airflow in the air environment. Typical examples of air environments can be tunnels and underground basements. From these complications comes the need to perform full-scale tests in order to detect the real thermal behaviour of an EW and analyse the interactions among different types of heat exchange modes acting simultaneously.

\subsection{Full-scale testing}

Within this study, a recently built energy wall at an underground train station located in western Switzerland is being tested through TRT accounting for a monitoring system that detects the hydro-thermal behaviour of the heat carrier fluid and the non-isothermal airflow in the tunnel.

The installation presents a 2-floored underground structure with $20.5 \mathrm{~m}$ deep walls, with a thickness of $1 \mathrm{~m}$ that sustain an excavation of $13 \mathrm{~m}$. Heat exchanger pipes are embedded in the walls and in the slab. The top floor is a technical room and the bottom floor is a train station.

There is a glass wall (architectural element) located $90 \mathrm{~cm}$ from the wall as a separation element between the concrete walls and the tunnel (Fig. 5).

The wall is constructed by modular elements of $2.5 \mathrm{~m}$ width, with heat exchangers embedded in it. Each modular element presents two U-loop pipes positioned closed to the edges of the element. Subsequent loops are connected in parallel; the inflow/outflow sections are located at the top floor. In this location, a heater [14] is positioned and connected to the heat exchangers (Fig. 5). The monitoring system is partially located at the top floor and partially at the station level. The heater measures the fluid temperature, velocity and flow rate, the room temperature and the power consumption. A thermal monitoring system is located inside the tunnel in order to measure the temperature, air velocity at two locations and deformations at the wall intrados. Fig. 5 shows a cross section view of the monitored site with the system details.

The test is executed following two steps. Initially, the fluid is circulated only (without heating), in order to detect the average temperature distribution along the heat exchangers: this temperature is affected by the tunnel and soil environments. The expected duration of this part is of 3 days. Secondly, a constant with time thermal power of $3 \mathrm{~kW}$ is applied to the heat exchangers for a duration of 14 days. Data are recorded every 10 minutes.

Subsequently, all the recorded data are processed. The effects on thermal interactions at the tunnel-wall interface are analysed and the thermal system results are interpreted in order to estimate the soil temperature. Different analytical and semi-analytical models are used to interpret and compare the TRT results.

Expected results relate to the definition of the average temperature around the EW, the average thermal conductivity of the soil mass, the estimation of the variations of the time dependent soil temperature and the thermal interactions between the wall and the tunnel. 


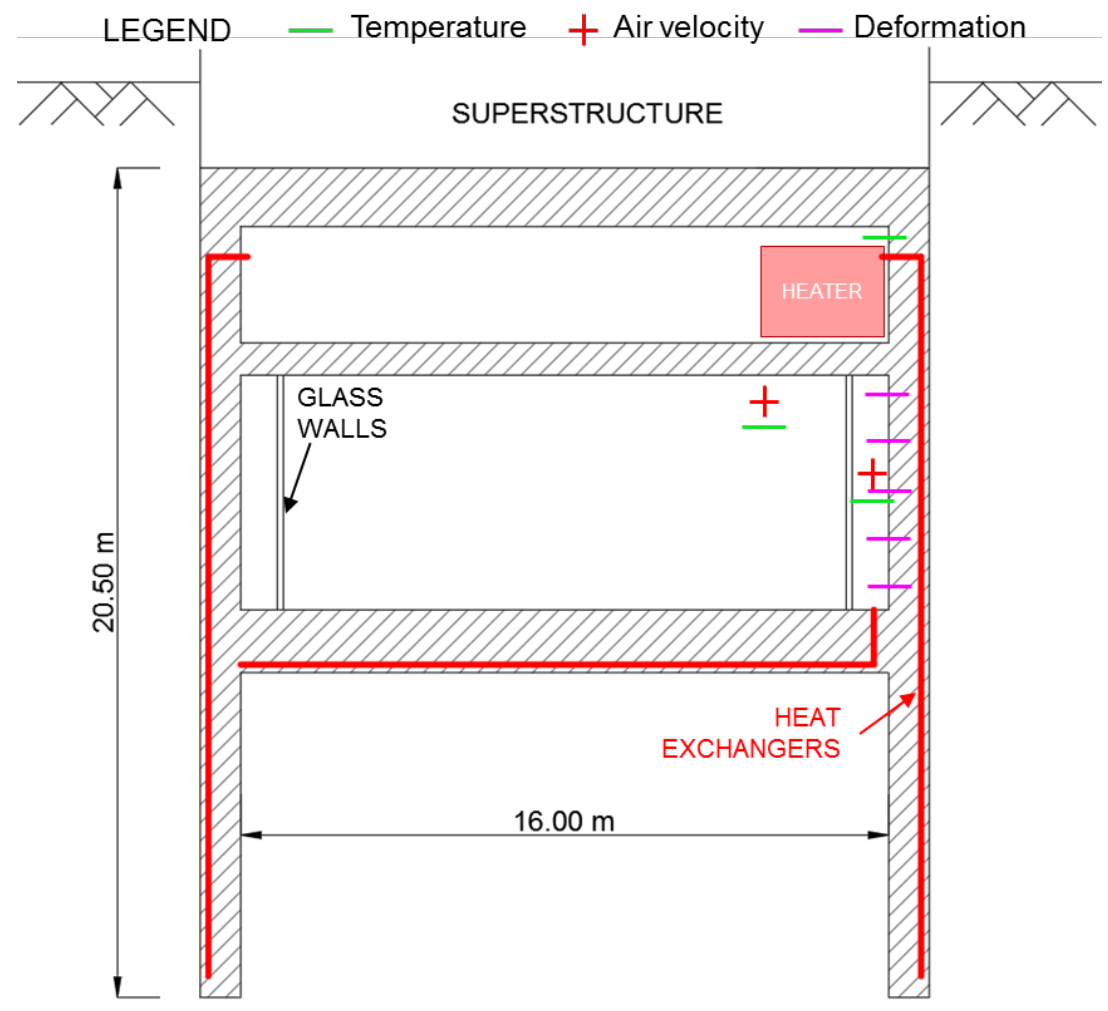

Fig. 5. Schematization of the monitoring system setup

\section{Conclusions}

Within this study, aspects related to the thermal behavior, thermal design and in situ testing of EWs have been discussed.

Hydro-thermal interactions between the EW and the surrounding soil present different effects depending on the groundwater flow direction.

Little interactions are recorded when the groundwater is perpendicular to the wall (i.e. generating a seepage below the infrastructure), while greater effects are recorded in the case of groundwater flow parallel to the EW. In such case, local variations of the seepage grid are generated at the wall-soil interface because of thermal activation. Moreover, hydraulically-induced thermal interactions among consequent pipe loops dramatically affect the thermal response of the heat exchangers.

Within this framework, a flowchart for the early-stage thermal design of EWs is proposed. The role of such flowchart is to help designers with a preliminary estimation of the energy quantities achievable by equipping an infrastructure with EWs depending on the hydro-thermal characterization of a site. Average values for the heat exchangers response are between 10 and 35 $\mathrm{W} / \mathrm{m}^{2}$ for summer and winter modes.

Moreover, the execution and analysis of a thermal response test on a recently built EW located in Switzerland is proposed. TRT are going to be executed and a thermo-mechanical monitoring system is envisaged. The feedback on this installation will be key for a deeper understanding on the thermo-hydro-mechanical behavior of such energy geostructures.

\section{References}

1. J.W. Lund, D. H. Freeston, and T. L. Boyd. Geothermics 40.3 (2011): 159-180.

2. COMSOL Inc., COMSOL Multiphysics Reference Manual, version 5.3, www.comsol.com.

3. N. Batini, A. Rotta Loria, P. Conti, D. Testi, W. Grassi and L. Laloui, Applied Thermal Engineering, vol. 86, no. 199-213, 2015

4. V. Gnielinski, Int. Chem. Eng., vol. 16 (1), no. 359-368, 1976

5. S. E. Haaland, Journal of Fluids Engineering 105.1 (1983): 89-90.

6. Zannin J., Ferrari A., Pousse M., Laloui L., Optimization of the energy exploitation and design of the heat exchangers embedded in an Energy Wall (in preparation), 2018a

7. Zannin J., Ferrari A., Pousse M., Laloui L., Hydro-thermal interactions in Energy Walls (in preparation), 2018b

8. Zannin J., Ferrari A., Pousse M., Laloui L., A flowchart for the early-stage design of energy walls (in preparation), 2018c

9. Choudary, A.: An approach to determine the thermal conductivity and diffusivity of a rock in situ. - PhDthesis, OSU, 1976

10. Mogensen, P., Proc. Int Conf Subs Heat Storage, 652-657, 1983

11. Hellström, G., I. Theory. 262 p., LTH, 1991

\footnotetext{
* Corresponding author: jacopo.zannin@epfl.ch
} 
12. Thermal Pile Standard, Ground Source Heat Pump Association (UK), 2012

13. T. Amis, C. Robinson and S. Wong, Proc. 11th DFI/EFFC Int. Conf. Geotechnical Challenges in Urban Regeneration. 2010

14. N. Mattsson, G. Steinmann and L. Laloui, Energy and buildings, 40(7) (2008), 1344-1352.

The authors gratefully acknowledge the financial support received from the European Union's Horizon 2020 research and innovation programme through the project TERRE 'Training Engineers and Researchers to Rethink Geotechnical Engineering for a low carbon future' under the grant agreement GA-2015-675762 (H2020-MSCAITN-2015). 